\title{
Recent extensions of U.S. unemployment benefits: search responses in alternative labor market states
}

Robert G Valletta

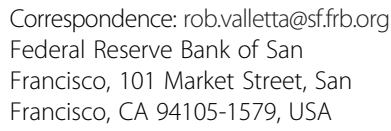

Correspondence: rob.valletta@sffrb.org Federal Reserve Bank of San

Francisco, 101 Market Street, San Francisco, CA 94105-1579, USA

\begin{abstract}
In response to the 2007-09 "Great Recession," the maximum duration of U.S. unemployment benefits was increased from the normal level of 26 weeks to an unprecedented 99 weeks. I estimate the impact of these extensions on job search, comparing them with the more limited extensions associated with the milder 2001 recession. The analyses rely on monthly matched microdata from the Current Population Survey. I find that a 10-week extension of UI benefits raises unemployment duration by about 1.5 weeks, with little variation across the two episodes. This estimate lies in the middle-to-upper end of the range of past estimates.

JEL codes: J64; J65

Keywords: Unemployment benefits; Job search
\end{abstract}

\section{Introduction}

During the recent "Great Recession" and its aftermath, unemployment insurance (UI) benefits in the United States were extended from the normal period of 26 weeks to the historically unprecedented maximum of 99 weeks. Rather than being rolled out comprehensively, the extensions were phased in slowly over time, and their full extent and exact timing varied across states based on state unemployment rates and other factors. This complex rollout created idiosyncratic variation in the maximum availability of UI benefits and hence provides a unique opportunity for assessing the effects of UI benefit extensions on job search behavior and unemployment duration.

Other recent research has examined the impact of the benefit extensions and found modest effects on search behavior and the overall unemployment rate but a larger effect on the share of unemployment that is long term (Rothstein 2011, Farber and Valletta 2013). Consistent with recent research using data for other countries (Card et al. 2007), the main estimated impact of the recent U.S. benefit extensions was prolonged labor force attachment rather than reduced job finding.

I add to the existing literature by providing new estimates of the impact of recent benefit extensions on search behavior and unemployment duration. Like Rothstein (2011) and Farber and Valletta (2013), I use matched data from consecutive months of the U.S. Current Population Survey (CPS). These data are combined with data on the monthly timing of UI extensions at the state level. The resulting data set is used for a 
discrete hazard analysis of the determinants of unemployment exits, focusing on the role of variation in the maximum availability of UI benefits across states and over time.

The paper makes three main contributions relative to the existing literature.

First, I estimate the response of unemployment duration to benefit duration and directly compare results for the recent benefit extensions with past estimates based on U.S. administrative data (Moffitt 1985; Katz and Meyer 1990; Card and Levine 2000; Jurajda and Tannery 2003). The findings suggest that the CPS household survey data provide a useful substitute for UI administrative data, which typically are available with a substantial lag (and are not yet generally available for the recent UI extension period).

Second, I compare the most recent episode of benefit extensions with the prior episode that occurred during a period of relatively favorable labor market conditions in the early 2000s. This enables an assessment of whether search responses vary based on the state of the labor market. Farber and Valletta (2013) focused on the duration of benefits rather than their generosity and found no meaningful difference in their job search impact under the very different labor market conditions prevailing during the benefit extension episodes of 2002-04 and 2008-12. However, they used a restricted specification that does not enable direct estimation of the response of unemployment duration to benefit duration.

Finally, I also compare the impact of the UI extensions on search behavior and outcomes for individuals who are eligible or ineligible to receive UI benefits. Individuals who are ineligible to receive UI benefits will not be directly affected by the availability of extended benefits and as such can in principle be used as a "placebo" group. However, the ineligible group may be affected by spillover effects or search externalities that increase their job-finding rates (Levine 1993; Lalive et al. 2013). Recent research suggests that such spillover effects are likely to be most pronounced when available jobs are rationed due to a severe downturn, such as that associated with the recent recession (Landais et al. 2010). My comparison of extended UI effects for eligible and ineligible individuals provides a test for search externalities that result from the implementation of broad labor market programs.

The paper proceeds as follows. Section 2 describes the UI extension programs and relevant past research, along with further discussion of the value-added of my paper. Sections 3 and 4 describe the matched CPS data and econometric framework, followed by the empirical results in Section 5. To preview, my results show that for the group most likely to be affected by UI extensions (job losers unemployed for at least 6 months), the estimated search response is in the middle-to-upper end of the range of past estimates based on administrative data. The estimates do not vary meaningfully across the two separate episodes analyzed (2000-04 and 2007-11). However, I uncover evidence of spillover effects that raise job-finding rates for ineligible individuals in states with high unemployment rates in the 2007-11 sample. I provide interpretation and discussion of these findings in the conclusion and suggest avenues for future research.

\section{UI extensions and job search}

\subsection{Normal and extended UI benefits in the United States}

UI benefits typically are available for 26 weeks in the United States under the joint federal-state Unemployment Compensation program established under the Social Security Act of 1935. About 95 percent of payroll employees are in jobs that are 
covered by the UI system. Unemployed individuals are eligible to receive benefits if they lost a job through no fault of their own (typically a permanent or temporary layoff) and they meet state-specific minimum requirements regarding work history and wages during the 12 to 15 month period preceding job loss. Availability for work and active job search are required for ongoing receipt of UI benefits, although the exact rules vary across states.

Normal UI benefits periodically are extended during episodes of economic distress, through a combination of permanent and temporary legislation. Table 1 lists the relevant programs for my analyses, their key provisions, and a timeline for the programs' inception and subsequent modifications that affect available UI benefit weeks. I discuss

Table 1 Timeline of extended UI programs (available weeks and state triggers)

\begin{tabular}{|c|c|c|}
\hline Program & $\begin{array}{c}\text { Effective dates } \\
\text { (plus sub programs) }\end{array}$ & $\begin{array}{l}\text { Maximum available weeks } \\
\quad \text { (and state triggers) }^{1}\end{array}$ \\
\hline Extended Benefits $(\mathrm{EB})^{2}$ & $\begin{array}{c}\text { 1970-Mar. } 1993 \\
\text { Mar. 1993-forward }\end{array}$ & $\begin{array}{c}13(\text { (IUR } \geq 5 \%) \\
13(\text { IUR } \geq 5 \% \text { or } 6 \%, \text { or } T U R \geq 6.5 \%) \\
20(\text { TUR } \geq 8 \%)\end{array}$ \\
\hline \multirow{4}{*}{$\begin{array}{l}\text { Temporary Extended Unemployment } \\
\text { Compensation (TEUC) }\end{array}$} & Mar. 2002-Mar. 2004 & \\
\hline & TEUC & 13 (all states) \\
\hline & TEUC-X & 13 (if on $E B$ or IUR $\geq 4 \%$ ) \\
\hline & Combined total & 26 \\
\hline \multirow{23}{*}{$\begin{array}{l}\text { Emergency Unemployment } \\
\text { Compensation (EUC) }\end{array}$} & Jul. 6, 2008 - Nov. 22, 2008 & 13 (all states) \\
\hline & Nov. 23, 2008-Nov. 7, 2009 & \\
\hline & Tier I & 20 (all states) \\
\hline & Tier $\|$ & 13 (IUR $\geq \%$ or TUR $\geq 8 \%$ ) \\
\hline & Combined total & 33 \\
\hline & Nov. 8, 2009-May 26, 2012 & \\
\hline & Tier I & 20 (all states) \\
\hline & Tier $\|$ & 14 (all states) \\
\hline & Tier III & 13 (TUR $\geq 6 \%$ or IUR $\geq 4 \%$ ) \\
\hline & Tier IV & $6(T \cup R \geq 8.5 \% \text { or IUR } \geq 6 \%)^{3}$ \\
\hline & Combined total & 53 \\
\hline & May 27, 2012-Sep. 1, 2012 & \\
\hline & Tier I & 20 (all states) \\
\hline & Tier $\|$ & 14 (TUR $\geq 6 \%)$ \\
\hline & Tier III & 13 (TUR $\geq 7 \%$ or IUR $\geq 4 \%$ ) \\
\hline & Tier IV & 6 (TUR $\geq 9 \%$ or IUR $\geq 6 \%$ ) \\
\hline & Combined total & 53 \\
\hline & Sep. 2, 2012-Dec. 28, 2013 & \\
\hline & Tier 1 & 14 (all states) \\
\hline & Tier ॥ & 14 (TUR $\geq 6 \%)$ \\
\hline & Tier III & $9(\mathrm{TUR} \geq 7 \%$ or IUR $\geq 4 \%)$ \\
\hline & Tier IV & 10 (TUR $\geq 9 \%$ or IUR $\geq 6 \%$ ) \\
\hline & Combined total & 47 \\
\hline
\end{tabular}

${ }^{1}$ States-specific triggers are based on the Insured Unemployment Rate (IUR) or Total Unemployment Rate (TUR) and generally include "look back" provisions (comparison of the rate used for the trigger to its rate over the prior 2-3 years). See text. ${ }^{2}$ Optional state triggers for EB program indicated. Up to 1981, the EB program included a national IUR trigger.

${ }^{3}$ From Feb. 19 through May 26, 2012, Tier IV allowed for 16 weeks if the state was not triggered on EB. 
the three relevant programs for my analysis in turn, focusing on the primary features that determine the state-time variation used in my analysis. ${ }^{1}$

The Federal-State Extended Benefits (EB) program, permanently authorized beginning in 1970, originally provided up to 13 weeks of additional UI benefits in states with high unemployment rates. It was amended in 1993 to allow for up to 20 weeks of additional benefits in states with especially high unemployment rates. The EB thresholds or triggers are based on the state's Insured Unemployment Rate (IUR) or Total Unemployment Rate (TUR), combined with the change over time ("lookback" provisions). ${ }^{2}$ States are allowed some latitude to choose different triggers based on the IUR or TUR. In recent years the triggers generally have been based on a TUR of 6.5 percent for a 13-week extension or 8.0 percent for 20 weeks, combined with a 10-percent increase in the TUR over the previous two years. Due to concerns that this lookback provision would cause some states to trigger off EB despite very high, sustained unemployment rates in recent years, it was modified in 2010 to allow states to rely on a three-year lookback period.

The EB program has been supplemented by temporary programs that have been used eight times since 1958, with the most recent episode beginning in 2008. Data on the timing of extensions at the state level are not available for the UI extension episodes prior to 2002. I therefore focus on the two episodes of UI extensions since 2002.

In response to the recession of 2001 and subsequent slow labor market recovery, the U.S. Congress passed the Temporary Extended Unemployment Compensation (TEUC) legislation, which was effective from March 2002 through early 2004. As shown in Table 1, this law extended UI availability by 13 weeks in all states and an additional 13 weeks in "high unemployment" states. The latter are defined based on an IUR of at least 4 percent and a lookback requirement specifying a 20-percent increase over the prior two years. Between normal UI benefits (26 weeks) and the EB and TEUC programs, a maximum of 72 weeks of UI benefit duration was available during this period. However, that maximum was reached in only a small number of states and therefore applied only to a limited number of individuals.

The severity of job loss and persistent labor market weakness during and after the recession of 2007-09 resulted in an unprecedented expansion of UI benefit availability. Between mid-2008 and late 2009, the Emergency Unemployment Compensation (EUC) program was slowly phased in. It initially provided for 13 additional weeks of benefits in July 2008. As listed in Table 1, additional benefit tiers (based on trigger thresholds) were added in December 2008 and November 2009. From that latter date until late 2012, the combined benefits availability through four EUC tiers remained at 53 weeks. In conjunction with normal UI benefit durations of 26 weeks and a maximum of 20 weeks through the EB program, the maximum duration of available UI benefits during this EUC program peak was 99 weeks. Table 1 also lists the subsequent legislative changes that raised the unemployment trigger thresholds in May 2012 and scaled back maximum EUC durations slightly in September (through changes in three of the four tiers). These provisions remained in place through the termination of the program at the end of 2013.

Information on maximum available UI duration through the EB and EUC programs for each state was released weekly by the U.S. Department of Labor (DOL). I used these weekly releases to construct a panel of UI availability for each state at a monthly 
frequency (to match the monthly CPS data used for the primary analyses). These data cover the last two periods of UI extensions. ${ }^{3}$ I focus on a measure of the maximum number of weeks that an eligible individual can receive in a particular state and month, labeled as the "potential benefit duration," or PBD (following Marinescu 2013). Variation in the PBD will be used as the measure of extended UI availability in the analyses below.

Figure 1 illustrates the variation in PBD over time (years 2000-late 2013) based on the various programs in effect. Panel A displays the maximum and minimum PBD measured across states in each sample month, and Panel B displays the average and standard deviation of the PBD across unemployed individuals (measured using a sample of all individuals identified as unemployed and eligible to receive UI in the CPS microdata; see the definition of eligibility in Section 3.2). ${ }^{4}$ Most states provide 26 weeks of UI during non-extension periods, although Massachusetts provides 30 and Montana provides 28 (hence the maximum exceeds 26 during non-extension periods).

Panel A shows that the PBD maximum/minimum spread across states was quite large (around 30-40 weeks) in the most recent extension episode and the preceding episode in the early 2000s. However, the number of states at or near the minimum in the recent

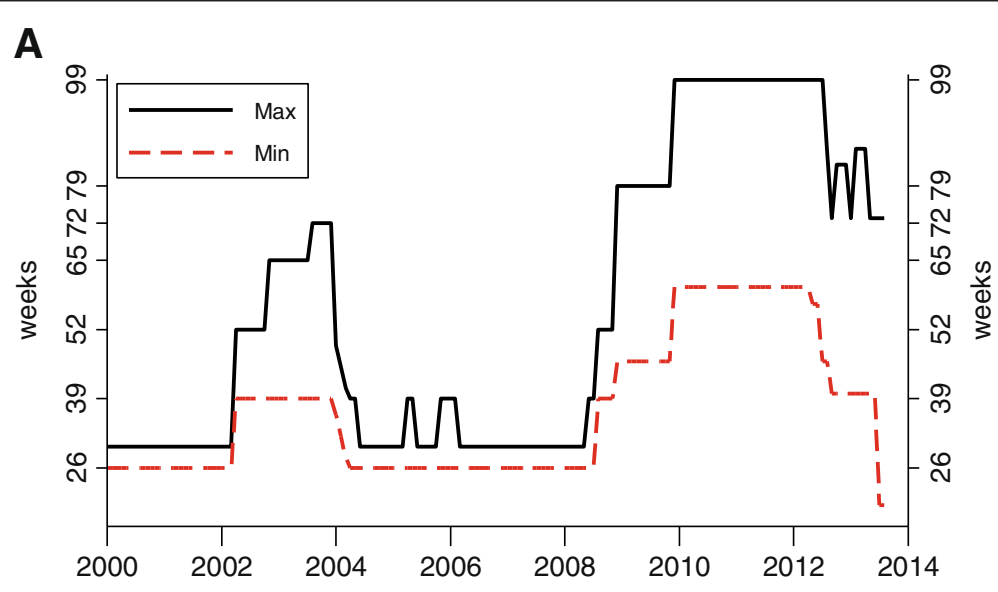

B

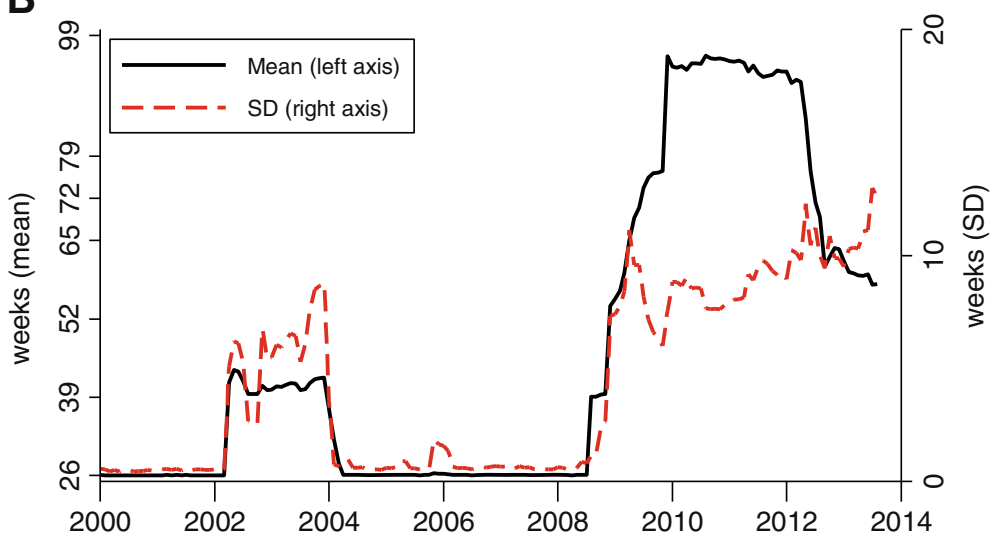

Figure 1 Variation in total weeks of UI available (Jan. 2000 through Aug. 2013). A. Maximum and minimum (across states) and B. Mean and Standard Deviation (weighted). Note: Author's calculations from U.S. Department of Labor data (see text). Panel B series calculated using CPS weighted unemployment observations. 
episode, and their labor force shares, were much smaller in the recent episode than in the preceding episode. This is reflected in Panel B, which shows that the average weeks of total UI eligibility reached about 96 in late 2009, implying that the typical unemployed individual was located in a state in which maximum UI eligibility was 99 weeks. In the early 2000s, maximum weeks of eligibility reached 72 . However, few states triggered on to the maximum extensions, and only about 13 additional weeks of UI beyond the normal 26 were available to the typical unemployed individual. The standard deviation displayed in Panel B indicates that the dispersion in total weeks available was only slightly higher in the recent episode than in the preceding one, implying that there is a similar degree of cross-state variation that can be used for estimates in both episodes. Panel B also shows a sharp drop in 2012 in the average PBD. This sharp drop occurred as unemployment rates dropped below the thresholds required for program continuation and some states reduced their normal UI duration below the prior low of 26 weeks. ${ }^{5}$

For the empirical analyses in subsequent sections, I use the extended UI data (and matched CPS data) through 2011 only. This choice is based on measurement issues that distort the estimated impact of the post-2011 reductions in PBD. The measurement issues reflect a fundamental asymmetry in the implementation of PBD changes caused by the state unemployment rate crossing a trigger threshold. An expansion causes an immediate increase in PBD for all eligible individuals, hence the timing and extent of the expansions is precisely measured. By contrast, when PBD is reduced in a state, individuals currently receiving benefits under the triggered-off program typically can continue to receive the full allotment of benefit weeks for which they qualified prior to the reduction in PBD. This allows them to continue receiving benefits for up to 20 weeks (4 to 5 months) after the rollback, which is the maximum number of weeks available through the EB program or the separate EUC tiers. As such, reductions in maximum weeks available provide very imprecise information about the timing of changes in PBD for affected individuals in a state, particularly in the context of the monthly frequency data that I use. The estimates for the post-2011 sample are dominated by the resulting measurement error (biased toward zero) and hence are excluded from my analyses.

\subsection{UI extension effects on unemployment duration}

Much of the existing research that assesses the impacts of unemployment benefits on search behavior focuses on benefit generosity (weekly/monthly payment amounts), which follows directly from the underlying theory of optimal UI (e.g. Baily 1978, Chetty 2008). However, a number of papers have directly examined the search response to U.S. benefit extensions and found that an increase in the maximum duration of benefits leads to an increase in average UI spell durations (notably Moffitt 1985, Katz and Meyer 1990, Card and Levine 2000, Jurajda and Tannery 2003, Schwartz 2013). ${ }^{6}$

More recently, researchers have turned their attention to the question of optimal benefit duration and whether it varies based on the business cycle or local economic conditions. In the classic formulation and extensions, optimal benefit generosity reflects a tradeoff between the welfare gains arising from insurance against income loss versus the disincentive or moral hazard effects of UI benefits on job search (Baily 1978, Chetty 2008). Recent research suggests that this tradeoff may depend on labor market 
conditions, for example through reduced arrival rates of job offers under weak labor market conditions that limit the moral hazard effect on job search. Kroft and Notowidigdo (2011) find direct empirical support for such effects based on joint variation in benefit generosity and state labor market conditions. Alternatively, if jobs are rationed when labor market conditions are weak, the resulting search externalities imply that the effects of increased program generosity will be smaller at the aggregate ("macro") level than is implied by the direct individual ("micro") responses (Landais et al. 2010). This gap between micro and macro estimates is likely to take the form of spillovers to individuals who are not eligible for the program expansion (Levine 1993, Lalive et al. 2013).

Direct empirical tests have yielded little or no support for variation in the effects of benefit extensions based on labor market conditions. Schmieder et al. (2012) used German data and found small effects of benefit extensions on unemployment duration, with limited variation in their behavioral impacts over the business cycle. Using U.S. data, Jurajda and Tannery (2003) found no variation in UI duration effects across two local labor markets with very different labor market conditions. Similarly, Farber and Valletta (2013) found no difference in UI extension effects on unemployment duration across the two episodes associated with the relatively mild recession of the early $2000 \mathrm{~s}$ and the more severe recent recession.

Past papers on the effects of benefit extensions generally have relied on administrative data on UI recipients. These data sets provide limited information on recipients' post-UI experiences and unemployment (e.g., whether they exit through job finding, continue searching, or withdraw from the labor force). In addition, the empirical focus on UI recipients in administrative data precludes analyses of indirect or spillover effects on UI nonrecipients and ineligibles. The use of survey data such as the CPS enables analyses along both dimensions. In the empirical work below, I examine how the unemployment experience of likely UI recipients responds to variation in the duration of UI benefits. I also test for search externalities by comparing outcomes for UI eligible and ineligible individuals across the extension episodes associated with the relatively mild recession of the early 2000s and the more severe recent recession. Relative to Farber and Valletta (2013), I use a less restrictive specification that enables direct estimation of the response of unemployment duration to benefit duration and direct comparison to prior findings.

\section{CPS matched transitions data}

\subsection{Matching and adjustments}

To analyze transitions out of unemployment and link them to changes in UI availability, I use matched monthly data on individual labor force participants from the U.S. CPS. The CPS is the monthly household survey that forms the basis for official U.S. labor force statistics, such as the unemployment rate. The pre-match sample is restricted to unemployed individuals age 16 and over during all months of the years 2000-04 and 2007-11. These correspond to the periods of labor market weakness and associated activation of extended benefits, as displayed earlier in Figure 1 (with about 12 months of pre-recession data included in each case, for normalization purposes). ${ }^{7}$

Due to the rotating sampling scheme used for the CPS, surveyed households and individuals are in the sample for two separate periods of 4 consecutive months (with an 
intervening 8-month period spent out of the sample). This enables month-to-month matching for about three-fourths of the sample (all but the "outgoing rotation groups" that are exiting the sample for eight months or permanently). The monthly match is based on household identifiers and validated by ensuring that the reported data on age, education, race, and gender do not conflict across matched observations.

I identify labor market transitions by comparing an individual's labor force status in month $t$ to that in month $t+1$. The data on UI benefits is matched based on the state's UI extension status as of the $5^{\text {th }}$ day of month $t+1$. Because the survey reference week is defined to always include the $12^{\text {th }}$ day of the month, the $5^{\text {th }}$ is the day immediately preceding the earliest possible day of the reference week. ${ }^{8}$ This ensures that any changes in PBD that could affect the individual's transition status between months $t$ and $t+1$ are incorporated. All other variables are measured at the time of the base transition month (month $t$ ).

A well-known concern regarding matched CPS data is the likelihood of spurious transitions in labor force status arising from inconsistent or error-ridden survey responses rather than meaningful changes (Abowd and Zellner 1985; Poterba and Summers 1986, 1995). Such spurious transitions could impart a downward bias to the estimated effect of UI extensions on unemployment exits and might also reduce the precision of the estimates. I therefore follow past research by adjusting the data to minimize the incidence of spurious transitions (Rothstein 2011, Farber and Valletta 2013). In particular, for individuals identified as leaving unemployment one month, either through job finding or labor force exit, and then returning to unemployment the next month, their records are recoded to show no transition (and the newly created observations are retained). This correction requires restriction of the final analysis sample to individuals who are observed to be in their first or second month of a consecutive fourmonth span in the sample. I refer to these below as "two-month forward matches".

To illustrate the impact of this correction on the measured transitions, Figure 2 displays the survivor curves-the percentage of spells that achieve a specific duration or

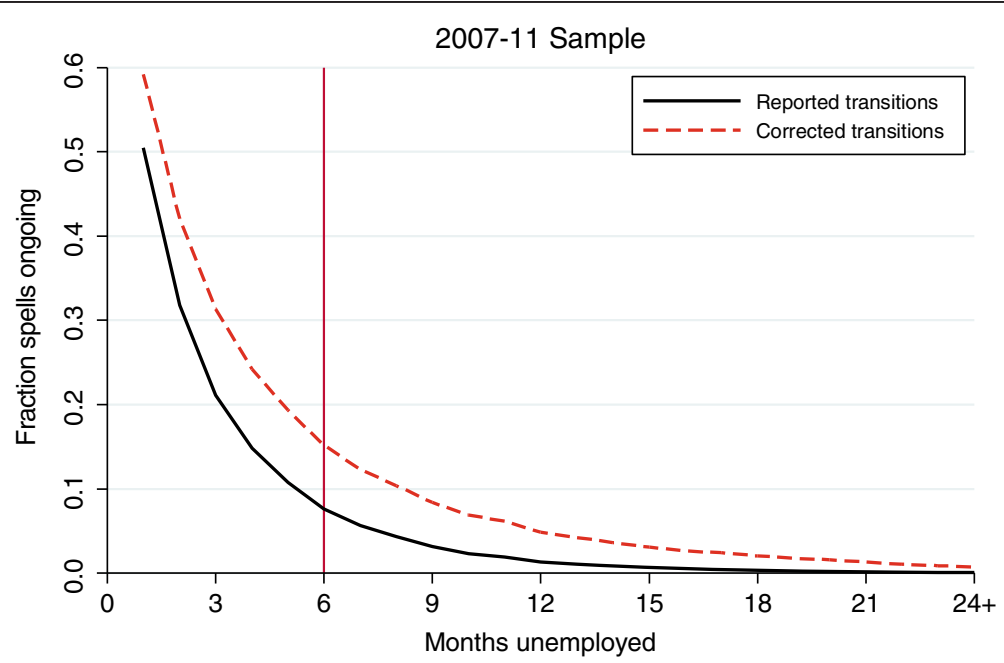

Figure 2 Unemployment survivor curves, 2007-11 sample. Note: Author's calculations from matched CPS data (weighted). 
greater-for the reported (uncorrected) and corrected transitions in the 2007-11 sample. The correction raises measured durations. The corrected data show that about 15 percent of unemployment spells last at least 6 months, approximately double the share reaching 6 months duration based on the unadjusted data. ${ }^{9}$ The correction brings the share of long-term unemployment closer to the corresponding share reported in the CPS cross-section data. ${ }^{10}$ The corrected transitions will be used for my main analyses, although I will also provide a comparison to results based on the larger sample of uncorrected transitions.

\subsection{Distinguishing UI eligibility}

An appropriate sample for analysis of the effect of UI benefits is a sample of unemployed individuals who are eligible to receive UI. However, because no direct information on receipt of UI benefits is available in the monthly CPS data, I rely on a proxy measure based on the reported reason for unemployment. Unemployed individuals who report job loss as the reason for unemployment are in principle eligible to receive UI, while those who report a voluntary separation or labor force entry (new or reentry) are in principle ineligible. I rely on this distinction below for the identification of UI eligible individuals and a placebo sample of ineligibles.

Past research shows that this distinction corresponds well to actual patterns of UI recipiency, although it is imperfect (Rothstein 2011, Farber and Valletta 2013). A worker who reports a job loss may not have sufficient prior employment experience to qualify for unemployment insurance or may have been fired for cause. In addition, an eligible worker may choose not to apply for benefits. These potential problems are mitigated somewhat by my empirical focus on job losers who have been unemployed for at least 6 months, since UI take-up among job losers generally increases with unemployment duration. More generally, my estimates should be interpreted as the effects of UI extensions on a sample of individuals who are potentially affected by the extensions. To the extent that misclassification exists for my samples of eligibles and ineligibles, my results for both groups may be biased toward zero.

\subsection{Descriptive statistics for the UI eligible/ineligible samples}

The basic characteristics of the matched CPS data extract to be used in the econometric analyses are displayed in Table 2. For the two separate analysis periods of 2000-04 and 2007-11, the sample is divided into UI eligible and ineligible individuals.

The top portion of Table 2 illustrates the construction of the analysis samples of matched observations from the initial complete samples of unemployed individuals in the monthly CPS surveys. ${ }^{11}$ The complete set of restrictions, including two-month forward matches and elimination of observations with missing values, leaves about 40 percent of the original sample of unemployed individuals. This pattern is consistent across the two sub-periods and also for UI eligible and ineligible individuals.

Table 2 shows that exit rates from unemployment are lower in the recent sample period than in the earlier sample period, as expected given that labor market conditions were more favorable in the earlier period. ${ }^{12}$ In both sample periods, exit rates generally are lower for UI eligible individuals (job losers) than for ineligibles (job leavers and labor force entrants). The difference is primarily due to exits out of the labor force rather than exits to employment. The substantial movements in and out of the labor 
Table 2 CPS matched sample formation and descriptive statistics

\begin{tabular}{|c|c|c|c|c|}
\hline & (1) & $(2)$ & (3) & (4) \\
\hline & \multicolumn{2}{|c|}{ 2007-2011 } & \multicolumn{2}{|c|}{ 2000-2004 } \\
\hline & $\begin{array}{l}\text { Ul eligible } \\
\text { (job losers) }\end{array}$ & $\begin{array}{l}\text { Ul ineligible } \\
\text { (job leavers and } \\
\text { LF entrants) }\end{array}$ & $\begin{array}{l}\text { Ul eligible } \\
\text { (job losers) }\end{array}$ & $\begin{array}{l}\text { UI ineligible } \\
\text { (job Leavers and } \\
\text { LF entrants) }\end{array}$ \\
\hline \multicolumn{5}{|l|}{ Sample steps } \\
\hline Currently unemployed & 173,391 & 123,276 & 107,327 & 102,417 \\
\hline Valid matches ${ }^{1}$ & 115,479 & 82,014 & 70,630 & 67,639 \\
\hline Matched two months forward & 73,022 & 51,818 & 43,546 & 42,210 \\
\hline $\begin{array}{l}\text { Final analysis samples } \\
\text { (recoded transitions, dropped missings) }^{2}\end{array}$ & 72,347 & 50,141 & 43,167 & 40,129 \\
\hline \multicolumn{5}{|l|}{ Exit rates from unemployment } \\
\hline Total exit rate & 0.253 & 0.362 & 0.336 & 0.445 \\
\hline Exit to employment & 0166 & 0.143 & 0.235 & 0.216 \\
\hline Exit to not in the labor force & 0.087 & 0.219 & 0.101 & 0.229 \\
\hline \multicolumn{5}{|l|}{ Unemployment duration $>=26$ weeks } \\
\hline Total exit rate & 0.171 & 0.282 & 0.241 & 0.343 \\
\hline Exit to employment & 0.078 & 0.086 & 0.125 & 0.119 \\
\hline Exit to not in the labor force & 0.093 & 0.196 & 0.116 & 0.223 \\
\hline \multicolumn{5}{|l|}{ Unemployment duration } \\
\hline Average & 28.2 & 27.4 & 16.7 & 16.6 \\
\hline Share unemployment duration $>=26$ weeks & 0.402 & 0.377 & 0.225 & 0.215 \\
\hline Share newly unemployed (<5 weeks) & 0.231 & 0.250 & 0.346 & 0.383 \\
\hline \multicolumn{5}{|l|}{ State variables (means) } \\
\hline Potential duration of UI benefits (PBD) & 74.2 & 69.4 & 33.0 & 32.2 \\
\hline Unemployment rate (percent) & 8.7 & 8.2 & 5.5 & 5.4 \\
\hline$\Delta \mathrm{In}$ (payroll emp.), 3-month annualized & -0.010 & -0.007 & 0.001 & 0.003 \\
\hline
\end{tabular}

force for ineligibles are consistent with the preponderance of labor force entrants in this group. ${ }^{13}$

Table 2 also shows that despite substantially higher exit rates for UI ineligibles, average reported duration is nearly the same for both groups. This likely reflects the recently documented tendency for labor force re-entrants to report unemployment durations upon re-entry that substantially exceed one month (Elsby et al. 2011). Such misreporting of unemployment duration is unlikely to affect the econometric analyses below, for two reasons: (i) in my analyses, reported duration is used only as a control variable and for coarse sample breaks rather than precise measurement of the timing of UI receipt and exhaustion; (ii) receipt of UI benefits is not restricted to self-reported unemployment spells but instead applies to prolonged periods of non-employment as well (Rothstein and Valletta 2014). The table also shows that state labor market conditions are slightly more adverse and available UI weeks are slightly longer for eligible than for ineligible individuals in the later sample period, which reflects the preponderance of job losers in states that were hit hardest by the recession. 
Additional comparison of the characteristics of the eligible and ineligible sub-samples is provided in Additional file 1: Table A1. In each period, the sample of ineligibles is younger and less educated, with a higher proportion of women. These differences in characteristics are as expected, given that the ineligible sample is dominated by labor force entrants. Finally, eligibles are more likely to be affiliated with cyclically sensitive sectors such as construction and durable manufacturing, while ineligibles are more concentrated in industry sectors that are characterized by tenuous employment attachment even during cyclical upturns, such as the retail and personal services sectors. ${ }^{14}$ On net, these descriptive statistics are broadly consistent with the delineation of the sample into UI eligible and ineligible groups.

Figures 3 and 4 provide more detail on unemployment exit rates, displaying them across the samples and by UI eligibility, broken down by unemployment duration (measured in months).

Figure 3 displays exit rates for the complete sample (eligibles and ineligibles together) in the two separate periods. It shows that overall exit rates were higher in the earlier sample period across all durations, with a noticeable uptick in exits at durations beyond 20 months in both samples. The gap in exit rates also widens somewhat beyond 6 months. To the extent that extended UI availability reduces exit rates, the widening gap in overall exit rates at higher durations may reflect the broader availability of extended UI benefits in the recent period, which reduced exit rates for the long-term unemployed in that period versus the earlier period.

Figure 4 separates the exit rate plots by sample period in the separate panels, and by UI eligibility status within each panel. Exit rates are generally higher for the ineligibles versus eligibles across all durations. The notable exception is at the longest durations (21 months or longer) in the 2007-11 sample, for which exit rates for eligibles and ineligibles are similar. Since benefit availability was extended up to 23 months in this period, the relative increase in exit rates at long durations for UI eligibles may reflect exhaustion of extended UI benefits. However, a similar pattern of increased exit rates at

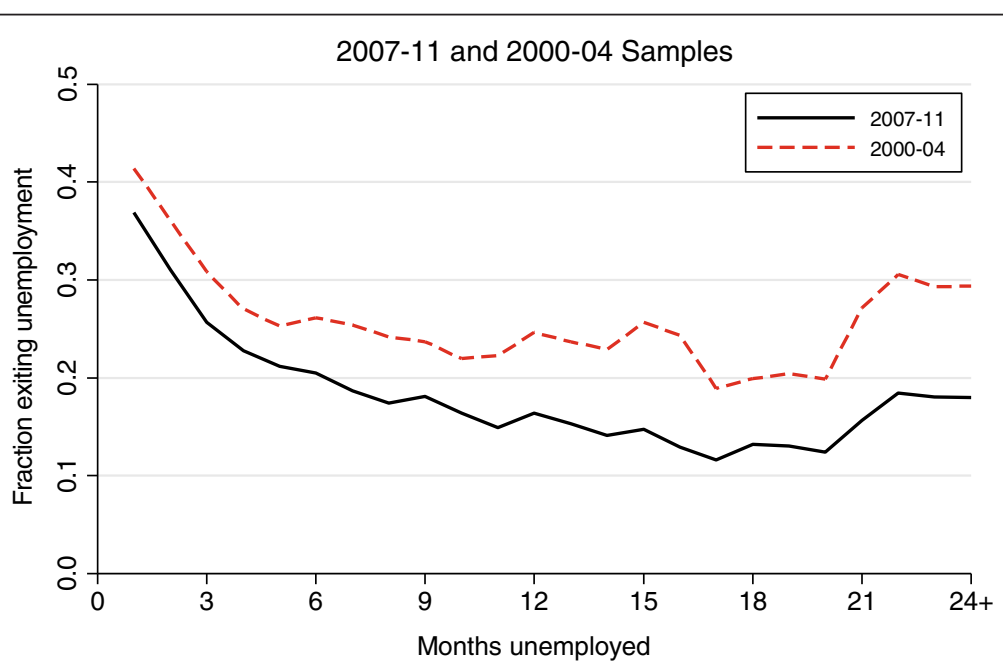

Figure 3 Unemployment exit rates 2007-11 and 2000-04 samples. Note: Author's calculations from matched CPS data (weighted). Transitions adjusted as described in the text. Values smoothed across adjacent duration bins. 

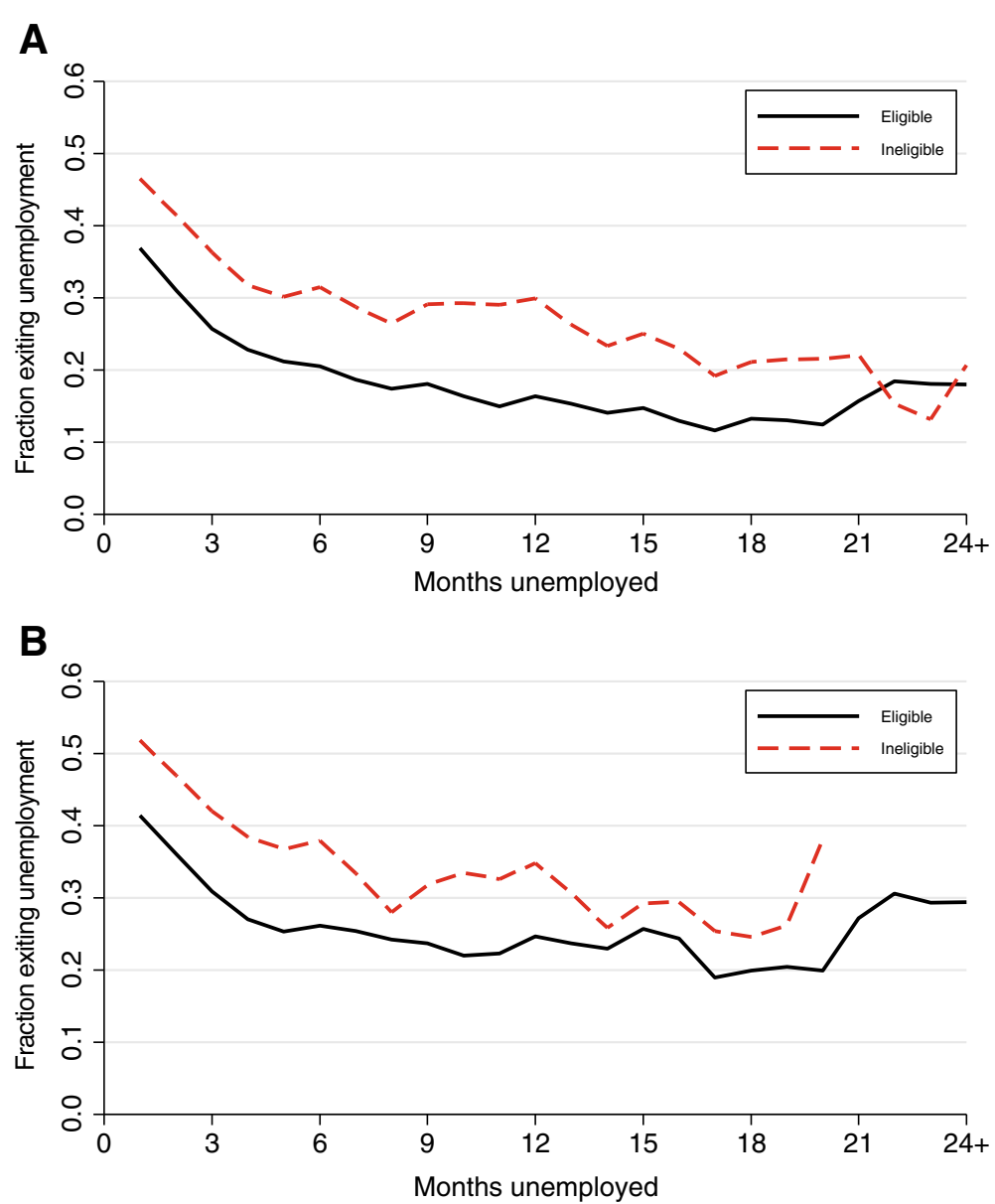

Figure 4 Unemployment exit rates, by sample and UI eligibility. A. 2007-11 sample and B. 2000-04 sample. Note: Author's calculations from matched CPS data (weighted). Transitions adjusted as described in the text. Values smoothed across adjacent duration bins. Durations for UI ineligibles in 2000-04 censored at 20 months (due to sparse data).

long durations in the earlier sample undercuts this explanation somewhat, because extended UI benefits would have been exhausted well before 21 months in that period (the PBD was 72 weeks or about 17 months during this period).

The exit rate plots are mildly suggestive of extended benefit effects on unemployment exit rates. The next section lays out a discrete time hazard framework for testing these effects more formally.

\section{Econometric framework}

My econometric analysis of extended UI effects on job search behavior and outcomes is based on a discrete time framework for the estimation of the probability of exiting unemployment. I estimate equations of the following form:

$$
\operatorname{Pr}\left(Y_{i s t}=1\right)=\delta \cdot\left(P B D_{s t} / 10\right)+\omega_{s}+\psi_{t}+\beta X_{i s t}+f\left(D_{i s t} ; \gamma\right)+\lambda Z_{s t}
$$

The dependent variable $Y$ is an indicator for whether an individual $i$ living in state $s$ who is unemployed in the survey reference week in month $t$ exits unemployment by month $t+1$ (i.e., reports no longer being unemployed in the reference week in the 
subsequent survey month). Exits from unemployment can occur either through job finding or labor force withdrawal. Estimation is based on the monthly panel of individuals formed by the CPS match. This is a standard "grouped duration data" approach that enables straightforward incorporation of my key time-varying covariates plus a flexible baseline hazard (see e.g. Wooldridge 2002, section 20.4). Below, I focus primarily on specifications that do not distinguish the exit route, although I also provide multinomial logit estimates based on the separate routes.

The main coefficient of interest is $\delta$, which measures the effect on unemployment exits of 10 additional weeks of extended UI benefits (potential benefit duration, or $P B D$ ), which varies across states and over time. Because the UI benefit extensions are most relevant for individuals who have been unemployed for at least 26 weeks, I follow Rothstein (2011) below in estimating additional specifications that allow the effects of PBD to vary across groups defined by whether they have been unemployed for at least 26 weeks.

The most basic specification estimated below incorporates a complete set of state dummies $\left(\omega_{s}\right)$ and date dummies $\left(\psi_{t}\right.$; one for each of the 60 months observed in the sample, less one). The state dummies account for differences in labor market conditions that are constant over time within states, while the date dummies account for changes in labor market conditions that are uniform across states. ${ }^{15}$

Subsequent specifications reported below add vectors of individual characteristics $(X)$, individual unemployment duration $(D)$, and state labor market characteristics $(Z)$. The vector $X$ is relatively standard and includes education (4 categories), age (7 categories), gender, marital status, the interaction of gender and marital status, an indicator for nonwhite race, and industry dummies (14 categories). ${ }^{16} \mathrm{D}$ is individual unemployment duration, which is incorporated based on the nonlinear function $f$; following Rothstein (2011), it includes terms for duration in weeks, its square, its inverse, and an indicator for newly unemployed individuals (duration $<5$ weeks). Finally, and most important, my final and preferred specification includes monthly measures of conditions in the state labor market, in particular cubics in the contemporaneous state unemployment rate and the rate of payroll employment growth (measured over the 3 months ending in the observation month, at an annual rate). Because the availability of extended UI benefits reflects state-specific labor market conditions, primarily the unemployment rate, inclusion of these variables is critical to ensure that the estimates are not contaminated by the direct correlation between UI extensions and deterioration in state labor market conditions. In all of the regressions, the standard errors are clustered by state.

Because the regressions include complete state and time (month) dummies, identification of the key parameter $\delta$ relies on differences in maximum available UI benefits (PBD) across states and over time, conditional on individual characteristics and state labor market conditions. The complexity of the extended UI trigger rules causes idiosyncratic and plausibly exogenous PBD variation across states and over time. It is common over my sample frame for two states to have identical unemployment rates in a particular month but PBDs that differ by 20 weeks or more. For example, in April of 2011, the unemployment rates in Texas and Arkansas were both 8.0 percent and payroll employment was growing at just under a 3 percent pace in both states. This suggests that labor market conditions that determine the job-finding prospects of 
unemployment individuals were very similar in the two states at that time. However, due to different state-specific rules regarding the EB program triggers and regular UI availability, eligible UI recipients had a PBD of 71 weeks in Arkansas and 93 weeks in Texas. In addition, given the trigger thresholds for UI extensions discussed in Section 2.1, it is also common to observe large differences in PBD's based only a small change over time in a state's unemployment rate or small differences between state unemployment rates. ${ }^{17}$ The differences in labor market conditions that trigger benefit extensions are controlled for through the flexible polynomials in the state unemployment rate and rate of job growth.

The main identifying assumption is that unobserved characteristics of state labor markets that affect job search behavior and outcomes are uncorrelated with variation over time in the availability of extended UI benefits in a state (conditional on the state labor market conditions that trigger the extensions). These identifying assumptions are less stringent than those used by Farber and Valletta (2013), who relied on within-state variation created by the comparison of individual unemployment duration to maximum available weeks of UI for each individual's state at a point in time. My less stringent assumptions are required in order to obtain direct estimates of the response of unemployment duration to changes in available UI weeks, which in turn enables direct comparison of my results to prior papers. However, this approach raises the possibility that my estimates are contaminated by unobserved correlations between economic conditions that affect search behavior and the availability of extended benefits. As noted above, this concern is mitigated by the inclusion of detailed controls for state labor market conditions. Examining the results for ineligible individuals provides additional information regarding the potential impact of omitted variables.

\section{Estimation results}

\subsection{Logit and multinomial logit regressions}

The main estimation results for UI eligible individuals are displayed in Table 3. Four different specifications are estimated for each sample period, with individual characteristics, unemployment duration, and state labor market conditions added sequentially to the baseline specification that includes only state and time dummies. Panel A shows the impact of UI benefit extensions (PBD) in the full sample of eligible individuals, while the second panel shows results for the same specifications but with the impact of UI benefit extensions estimated separately for individuals who have been unemployed for at least 26 weeks or fewer than 26 weeks ( 6 months). ${ }^{18}$ The estimates listed in both panels are based on transformed logit coefficients. They represent the marginal effects of 10 additional weeks of extended UI benefits on the probability of existing from unemployment (expressed as proportions, like the baseline exit rates in Table 2 and Figures 3 and 4).

For the full sample results in Panel A, the column (1) estimate for the 2007-11 sample indicates that a UI extension of 10 weeks reduces the probability of exiting unemployment by about 1 percentage point. This estimate is halved and becomes statistically insignificant as the complete sets of control variables are added. No significant estimates for the overall PBD effect are found for the 2000-04 sample.

By contrast, Panel B of Table 3 shows that for both time periods the estimated negative effect of UI benefit extensions on unemployment exits is relatively robust for 
Table 3 Logit regression results, Pr (Exit from unemployment), UI ELIGIBLE, marginal effects of of 10 additional UI weeks

\begin{tabular}{|c|c|c|c|c|c|c|c|c|}
\hline & (1) & $(2)$ & (3) & (4) & (5) & (6) & (7) & (8) \\
\hline & \multicolumn{8}{|c|}{ Panel A: Single UI weeks variable } \\
\hline & \multicolumn{4}{|c|}{ 2007-11 } & \multicolumn{4}{|c|}{$2000-04$} \\
\hline \multicolumn{9}{|l|}{ UI variables } \\
\hline \multirow[t]{3}{*}{$\begin{array}{l}\text { Potential benefit } \\
\text { duration (PBD) }\end{array}$} & $\begin{array}{c}-0.0106^{* *} \\
(0.00331)\end{array}$ & $\begin{array}{l}-0.0104^{* *} \\
(0.00321)\end{array}$ & $\begin{array}{c}-0.00788^{* *} \\
(0.00293)\end{array}$ & $\begin{array}{l}-0.00529 \\
(0.00341)\end{array}$ & $\begin{array}{l}-0.00625 \\
(0.007763)\end{array}$ & $\begin{array}{l}-0.00808 \\
(0.00691)\end{array}$ & $\begin{array}{l}-0.00759 \\
(0.00638)\end{array}$ & $\begin{array}{l}-0.0103 \\
(0.00855)\end{array}$ \\
\hline & \multicolumn{8}{|c|}{ Panel B: Separate effects of UI weeks for unemployment duration $>=$ or $<26$ weeks } \\
\hline & \multicolumn{4}{|c|}{ 2007-11 } & \multicolumn{4}{|c|}{$2000-04$} \\
\hline PBD (dur >= 26) & $\begin{array}{l}-0.0174^{* *} \\
(0.000326)\end{array}$ & $\begin{array}{l}-0.0165^{* *} \\
(0.00318)\end{array}$ & $\begin{array}{l}-0.0116^{* *} \\
(0.00333)\end{array}$ & $\begin{array}{l}-0.00918^{*} \\
(0.00375)\end{array}$ & $\begin{array}{l}-0.0299^{* *} \\
(0.00672)\end{array}$ & $\begin{array}{l}-0.024^{* *} \\
(0.00632)\end{array}$ & $\begin{array}{l}-0.0183^{* *} \\
(0.00700)\end{array}$ & $\begin{array}{l}-0.0212^{* *} \\
(0.00822)\end{array}$ \\
\hline PBD $($ dur $<=26)$ & $\begin{array}{l}-0.00333 \\
(0.00316)\end{array}$ & $\begin{array}{l}-0.00377 \\
(0.00307)\end{array}$ & $\begin{array}{l}-0.00574^{*} \\
(0.00289)\end{array}$ & $\begin{array}{l}-0.00323 \\
(0.00334)\end{array}$ & $\begin{array}{l}-0.000704 \\
(0.00657)\end{array}$ & $\begin{array}{l}-0.00345 \\
(0.00620)\end{array}$ & $\begin{array}{l}-0.00441 \\
(0.00661)\end{array}$ & $\begin{array}{l}-0.00702 \\
(0.00891)\end{array}$ \\
\hline \multicolumn{9}{|l|}{$\begin{array}{l}\text { Additional } \\
\text { controls: }\end{array}$} \\
\hline State/time & Y & Y & Y & Y & Y & Y & Y & Y \\
\hline $\begin{array}{l}\text { Individual } \\
\text { characteristics }\end{array}$ & $N$ & Y & Y & Y & $\mathrm{N}$ & Y & Y & Y \\
\hline $\begin{array}{l}\text { Unemployment } \\
\text { duration }\end{array}$ & $N$ & $N$ & Y & Y & $N$ & $N$ & Y & Y \\
\hline $\begin{array}{l}\text { State unemp. } \\
\& \text { emp. growth } \\
\text { (cubics) }\end{array}$ & $N$ & $N$ & $N$ & Y & $N$ & $N$ & $\mathrm{~N}$ & Y \\
\hline Observations & 72,347 & 72,347 & 72,347 & 72,347 & 43,167 & 43,167 & 43,167 & 43,167 \\
\hline
\end{tabular}

Standard errors in parentheses (clustered by state). ${ }^{* *} \mathrm{p}<0.01,{ }^{*} \mathrm{p}<0.05$.

Notes: Numbers are transformed logit coefficients, expressed as marginal effects on the probability of observing an unemployment exit. See text for the complete list of additional controls.

individuals who have been unemployed for at least 6 months (26 weeks) and hence are directly affected by the benefit extensions. In the 2007-11 sample, the PBD coefficient for the long duration group is cut approximately in half by the inclusion of individual characteristics and state labor market controls. However, it remains highly significant in all columns. The estimate in the fourth column is significant at nearly the 1-percent level and implies a reduction in the unemployment exit probability of about 1 percentage point (relative to a baseline exit rate of about 17 percent for UI eligibles unemployed for at least 6 months; see Table 2). By contrast, for individuals who have been unemployed for less than 6 months and hence are not directly affected by the benefit expansions, the estimated PBD effects are small and highly insignificant in general. ${ }^{19}$

A similar pattern across the columns of Panel B in Table 3 is evident for the 2000-04 sample, but with a larger estimated effect of benefit extensions on unemployment exits. For this earlier sample period, column (8) shows approximately a 2 percentage point reduction in the probability of exiting unemployment (relative to a baseline probability of about 24 percent in Table 2). Although this estimate is substantially larger than the corresponding estimate for the 2007-11 sample (column 4), the exit rates are also larger in the 2000-04 sample, suggesting that the impact on unemployment duration may not differ by much. The difference between the two estimates is not statistically significant at conventional levels (the $t$-statistic on the difference 
between them is approximately 1.0). I return to this issue of relative magnitudes in the next sub-section.

The results in Table 3 are based on the sample of 2-month forward matches that correct for potentially spurious unemployment transitions, as discussed in Section 3.1. The Additional file 1: Table A3 lists parallel results based on the larger sample of uncorrected transitions. The coefficients on PBD are slightly larger and more precisely estimated for the 2007-11 sample using the uncorrected data, but substantially smaller and less precise in the 2000-04 sample. The findings for the 2000-04 sample illustrate the importance of using the corrected data, which is reinforced by the magnitude calculations discussed in the next sub-section.

Table 4 lists the results for the same specifications as Table 3, but with the sample restricted to individuals who are not eligible to receive UI benefits. ${ }^{20}$ The estimated effects of benefit extensions generally are small and highly insignificant, especially in the specifications with complete controls, and they vary in sign. This is true for the overall sample effect (Panel A) and also the effect for individuals unemployed for at least 26 weeks (Panel B). The absence of any negative effects of $\mathrm{PBD}$ on exits for this placebo sample of ineligible individuals suggests that PBD is not serving as a proxy for unobserved, adverse economic conditions. In conjunction with the Table 3 results for eligible individuals who have been unemployed for less than 6 months, these results for ineligibles provide further evidence that the effects of benefit extensions are largely restricted to individuals who are eligible to receive them. ${ }^{21}$

Table 4 Logit regression results, Pr (Exit from unemployment), UI INELIGIBLE, marginal effects of 10 additional UI weeks

\begin{tabular}{|c|c|c|c|c|c|c|c|c|}
\hline & (1) & $(2)$ & (3) & (4) & (5) & (6) & (7) & (8) \\
\hline & \multicolumn{8}{|c|}{ Panel A: Single UI weeks variable } \\
\hline & \multicolumn{4}{|c|}{ 2007-11 } & \multicolumn{4}{|c|}{ 2000-04 } \\
\hline \multicolumn{9}{|l|}{ UI variables } \\
\hline \multirow[t]{3}{*}{$\begin{array}{l}\text { Potential benefit } \\
\text { duration (PBD) }\end{array}$} & $\begin{array}{l}0.000573 \\
(0.00486)\end{array}$ & $\begin{array}{l}0.000943 \\
(0.00505)\end{array}$ & $\begin{array}{c}0.00105 \\
(0.00480)\end{array}$ & $\begin{array}{c}0.00446 \\
(0.00597)\end{array}$ & $\begin{array}{l}0.00313 \\
(0.00728)\end{array}$ & $\begin{array}{c}0.00243 \\
(0.00689)\end{array}$ & $\begin{array}{l}0.000739 \\
(0.00718)\end{array}$ & $\begin{array}{c}0.00327 \\
(0.00719)\end{array}$ \\
\hline & \multicolumn{8}{|c|}{ Panel B: Separate effects of UI weeks for unemployment duration $>=$ or $<26$ weeks } \\
\hline & \multicolumn{4}{|c|}{ 2007-11 } & \multicolumn{4}{|c|}{ 2000-04 } \\
\hline PBD (dur >=26) & $\begin{array}{l}-0.00578 \\
(0.00499)\end{array}$ & $\begin{array}{l}-0.00445 \\
(0.00520)\end{array}$ & $\begin{array}{l}-0.00102 \\
(0.00482)\end{array}$ & $\begin{array}{c}0.00220 \\
(0.00633)\end{array}$ & $\begin{array}{c}0.0216^{* *} \\
(0.00825)\end{array}$ & $\begin{array}{c}0.0176^{*} \\
(0.00781)\end{array}$ & $\begin{array}{c}-0.000962 \\
(0.00953)\end{array}$ & $\begin{array}{c}0.00101 \\
(0.00945)\end{array}$ \\
\hline PBD (dur<26) & $\begin{array}{c}0.00631 \\
(0.00504)\end{array}$ & $\begin{array}{c}0.00574 \\
(0.00514)\end{array}$ & $\begin{array}{c}0.00259 \\
(0.00498)\end{array}$ & $\begin{array}{c}0.00601 \\
(0.00589)\end{array}$ & $\begin{array}{c}0.00905 \\
(0.00815)\end{array}$ & $\begin{array}{c}0.00732 \\
(0.00767)\end{array}$ & $\begin{array}{c}0.00122 \\
(0.00705)\end{array}$ & $\begin{array}{c}0.00393 \\
(0.00706)\end{array}$ \\
\hline \multicolumn{9}{|l|}{ Additional controls: } \\
\hline State/time & Y & Y & Y & Y & Y & Y & Y & Y \\
\hline Individual characteristics & $\mathrm{N}$ & Y & Y & Y & $\mathrm{N}$ & Y & Y & Y \\
\hline $\begin{array}{l}\text { Unemployment } \\
\text { duration }\end{array}$ & $N$ & $\mathrm{~N}$ & Y & Y & N & $\mathrm{N}$ & Y & Y \\
\hline $\begin{array}{l}\text { State unemp. \& emp. } \\
\text { growth (cubics) }\end{array}$ & $N$ & N & N & Y & N & N & N & Y \\
\hline Observations & 50,141 & 50,141 & 50,141 & 50,141 & 40,129 & 40,129 & 40,129 & 40,129 \\
\hline
\end{tabular}

Standard errors in parentheses (clustered by state). ${ }^{* *} \mathrm{p}<0.01,{ }^{*} \mathrm{p}<0.05$.

Notes: Numbers are transformed logit coefficients, expressed as marginal effects on the probability of observing an unemployment exit. See text for the complete list of additional controls. 
Table 5 Multinomial logit regression results, UI ELIGIBLE, separate exit routes: to employment or not in labor force (NILF); marginal effects of 10 additional UI weeks

\begin{tabular}{|c|c|c|c|c|}
\hline & (1) & $(2)$ & (3) & (4) \\
\hline & \multicolumn{4}{|c|}{ Panel A: Single UI weeks variable } \\
\hline & \multicolumn{2}{|c|}{ 2007-11 } & \multicolumn{2}{|c|}{ 2000-04 } \\
\hline & Exit to employment & Exit to NILF & Exit to employment & Exit to NILF \\
\hline \multicolumn{5}{|l|}{ UI variables } \\
\hline \multirow[t]{4}{*}{$\begin{array}{l}\text { Potential benefit duration } \\
\text { (PBD) }\end{array}$} & $\begin{array}{l}-0.00150 \\
(0.00288)\end{array}$ & $\begin{array}{l}-0.00359 \\
(0.00214)\end{array}$ & $\begin{array}{l}-0.00142 \\
(0.00635)\end{array}$ & $\begin{array}{l}-0.00916 \\
(0.00637)\end{array}$ \\
\hline & \multicolumn{4}{|c|}{ Panel B: Separate effects for unemployment duration $>=$ or $<26$ weeks } \\
\hline & \multicolumn{2}{|c|}{ 2007-11 } & \multicolumn{2}{|c|}{$2000-04$} \\
\hline & Exit to employment & Exit to NILF & Exit to employment & Exit to NILF \\
\hline PBD (dur $>=26)$ & $\begin{array}{l}-0.00326 \\
(0.00310)\end{array}$ & $\begin{array}{l}0.00514^{*} \\
(0.00224)\end{array}$ & $\begin{array}{l}-0.00097 \\
(-0.00614)\end{array}$ & $\begin{array}{l}-0.0175^{* *} \\
(0.00605)\end{array}$ \\
\hline PBD $($ dur $<26)$ & $\begin{array}{l}-0.00066 \\
(0.00284)\end{array}$ & $\begin{array}{l}-0.00207 \\
(0.00208)\end{array}$ & $\begin{array}{l}-0.00068 \\
(0.00674)\end{array}$ & $\begin{array}{l}-0.00629 \\
(0.00637)\end{array}$ \\
\hline \multicolumn{5}{|l|}{ Additional controls } \\
\hline State/time & Y & Y & Y & Y \\
\hline Individual characteristics & Y & Y & Y & Y \\
\hline Unemployment duration & Y & Y & Y & Y \\
\hline Stateunemp.\& emp.growth (cubics) & Y & Y & Y & Y \\
\hline Observations & 72,347 & 72,347 & 43,167 & 43,167 \\
\hline
\end{tabular}

Standard errors in parentheses (clustered by state). ${ }^{* *} \mathrm{p}<0.01,{ }^{*} \mathrm{p}<0.05$.

Notes: Numbers are transformed logit coefficients, expressed as marginal effects on the probability of observing an unemployment exit. See text and Appendix Table A2 for the complete list of additional controls.

Table 5 shows the separate effects of UI extensions on unemployment exits through the separate routes of employment (job finding) and out of the labor force (not in labor force, or NILF). I rely on a multinomial logit specification, which treats the causespecific exit rates as independent. Consistent with Rothstein (2011) and Farber and Valletta (2013), UI extensions lengthen unemployment spells primarily through reducing labor force exits rather than job finding. For both sample periods, the only statistically significant estimates are for the PBD effect on labor force exits for individuals unemployed for at least 26 weeks, and the magnitudes of the NILF estimates are uniformly much larger than the magnitudes of the job-finding estimates. ${ }^{22}$

As noted in the Introduction and literature review in Section 2.2, some past research has uncovered spillover or search externality effects on ineligible individuals, which are most likely under weak labor market conditions (Landais et al. 2010). In particular, to the extent that benefit extensions reduce job finding by UI-eligible individuals, this may open up available jobs for UI-ineligible individuals, whose job finding rate will rise.

Table 6 investigates the possibility of spillovers by providing regression results similar to those in Table 4 for ineligibles, but with the dependent variable reflecting unemployment exits through job finding only. I provide two sets of results for each period, for the basic specification from prior tables (columns 1 and 3) and for an expanded specification that includes interactions between the PBD variables and the state unemployment rate. The basic specification implies no spillover effects of increasing in benefit availability for ineligible individuals: the coefficients on PBD are 
Table 6 Logit regression results, Pr (Exit to employment), UI INELIGIBLE (includes interactions with state unemployment rate), marginal effects of 10 additional UI weeks

\begin{tabular}{|c|c|c|c|c|}
\hline & (1) & $(2)$ & (3) & (4) \\
\hline & \multicolumn{4}{|c|}{ Panel A: Single UI weeks variable } \\
\hline & \multicolumn{2}{|c|}{$2007-11$} & \multicolumn{2}{|c|}{$2000-04$} \\
\hline \multicolumn{5}{|l|}{ UI variables } \\
\hline $\begin{array}{l}\text { Potential benefit duration } \\
\text { (PBD) }\end{array}$ & $\begin{array}{c}0.00328 \\
(0.00344)\end{array}$ & $\begin{array}{c}-0.0262^{* *} \\
(0.00901)\end{array}$ & $\begin{array}{l}0.000440 \\
(0.00610)\end{array}$ & $\begin{array}{c}0.0511 \\
(0.0334)\end{array}$ \\
\hline \multirow[t]{3}{*}{$\mathrm{PBD}$ * state unemp. rate } & - & $\begin{array}{l}0.00334^{* *} \\
(0.000994)\end{array}$ & - & $\begin{array}{l}-0.00716 \\
(0.00448)\end{array}$ \\
\hline & \multicolumn{4}{|c|}{$\begin{array}{l}\text { Panel B: Separate effects for unemployment } \\
\text { duration }>=\text { or }<26 \text { weeks }\end{array}$} \\
\hline & \multicolumn{2}{|c|}{$2007-11$} & \multicolumn{2}{|c|}{$2000-04$} \\
\hline $\mathrm{PBD}$ (dur>=26) & $\begin{array}{c}0.00440 \\
(0.00361)\end{array}$ & $\begin{array}{c}-0.0259^{* *} \\
(0.00931)\end{array}$ & $\begin{array}{c}0.00193 \\
(0.00844)\end{array}$ & $\begin{array}{l}0.0603 \\
(0.0398)\end{array}$ \\
\hline PBD $($ dur $<26)$ & $\begin{array}{c}0.00275 \\
(0.00342)\end{array}$ & $\begin{array}{r}-0.0256^{* *} \\
(0.00907)\end{array}$ & $\begin{array}{l}0.000137 \\
(0.00591)\end{array}$ & $\begin{array}{c}0.0494 \\
(0.0327)\end{array}$ \\
\hline $\begin{array}{l}\mathrm{PBD}(\mathrm{dur}>=26)^{*} \\
\text { state unemp. rate }\end{array}$ & - & $\begin{array}{l}0.00339^{* *} \\
(0.00102)\end{array}$ & - & $\begin{array}{l}-0.00812 \\
(0.00495)\end{array}$ \\
\hline $\begin{array}{l}\mathrm{PBD}(\text { dur }<26)^{*} \\
\text { state unemp. rate }\end{array}$ & - & $\begin{array}{l}0.00323^{* *} \\
(0.00100)\end{array}$ & - & $\begin{array}{l}-0.00700 \\
(0.00445)\end{array}$ \\
\hline \multicolumn{5}{|l|}{ Additional controls } \\
\hline State/time & Y & Y & Y & Y \\
\hline Individual characteristics & Y & Y & Y & Y \\
\hline Unemployment duration & Y & Y & Y & Y \\
\hline \multirow[t]{2}{*}{ State unemp. \& emp. growth (cubics) } & Y & Y & Y & Y \\
\hline & Y & Y & Y & Y \\
\hline Observations & 50,141 & 50,141 & 40,129 & 40,129 \\
\hline
\end{tabular}

Standard errors in parentheses (clustered by state). ${ }^{* *} \mathrm{p}<0.01,{ }^{*} \mathrm{p}<0.05$.

Notes: Numbers are transformed logit coefficients, expressed as marginal effects on the probability of observing an unemployment exit to employment. See text for the complete list of additional controls.

uniformly small and insignificant in columns (1) and (3). However, column (2) provides evidence for spillover effects in high unemployment states in the 2007-11 sample. The interaction effects between the PBD variables and the state unemployment rate are positive and precisely estimated, with very similar point estimates of the PBD effect for individuals who have been unemployed for greater or less than six months.

The implied spillover effects for ineligibles in the 2007-11 sample are limited to states with very high unemployment rates. In particular, combining the coefficients on PBD and its interaction with the state unemployment rate implies essentially a zero effect of PBD changes at an unemployment rate of 7.8 percent. $^{23}$ This is slightly below the weighted sample average state unemployment rate of 8.6 percent in my 2007-11 sample (as expected, given the essentially zero estimate for PBD in column 1). However, in a state with an 11 percent unemployment rate, which is around the $80^{\text {th }}$ percentile of the weighted distribution of state unemployment rates in the 2007-11 sample, an additional 10 weeks of available UI benefits (PBD) increases job finding rates for ineligibles by about 1 percentage point. ${ }^{24}$ This is a meaningful impact relative to the base job finding rate of 14.3 percent in the 2007-11 sample of ineligibles (Table 2, column 2). 
The estimated interaction effects between PBD and state unemployment rates on job finding by ineligible individuals raise the possibility of similar interaction effects for eligible individuals. I therefore estimated all of the regressions for the eligible samples from Tables 3 and 5 with interactions between the PBD variables and the state unemployment rate. None of the interaction coefficients approached conventional levels of statistical significance (results available on request).

\subsection{Translation to unemployment duration}

The estimated coefficients for the specifications with complete controls in Table 3 suggest a moderate effect of UI benefit extensions on unemployment exits for individuals who are directly affected by the extensions. In particular, for job losers who have been unemployed for at least 26 weeks, 10 additional weeks of UI benefits reduce unemployment exit rates by about 1-2 percentage points (relative to baseline exit rates of about 17-25 percent). In this section, I translate these estimates into effects on expected duration of unemployment, for direct comparison to past results regarding the effects of UI benefit extensions.

Conversion of the effects on unemployment exits into effects on unemployment duration is straightforward. Let $P_{t}=$ (the fraction continuing in unemployment from month $t$ to $t+1)$ which is just (1-(exit rate)) . Then the expected or average duration of a completed spell of unemployment $(S)$ is as follows (see e.g. Sider 1985):

$$
\begin{aligned}
\mathrm{S} & =\left(1-\mathrm{P}_{1}\right)+2 \cdot \mathrm{P}_{1} \cdot\left(1-\mathrm{P}_{2}\right)+3 \cdot \mathrm{P}_{1} \cdot \mathrm{P}_{2} \cdot\left(1-\mathrm{P}_{3}\right)+\ldots \\
& =1+\mathrm{P}_{1}+\mathrm{P}_{1} \cdot \mathrm{P}_{2}+\mathrm{P}_{1} \cdot \mathrm{P}_{2} \cdot \mathrm{P}_{3}+\ldots
\end{aligned}
$$

I apply this formula to the sample of eligible individuals unemployed for at least 26 weeks. For this group, I obtain expected completed duration $S$ by setting $P_{1}$ through $P_{6}$ equal to 1 (to ensure spell lengths of at least 6 months) and then using the observed empirical continuation rates to calculate $P_{7}$ through $P_{24}$, which are then plugged into the formula for $S$ above. ${ }^{25}$ This represents duration with the extensions as observed. To assess the impact of the extensions on expected duration, I obtain a counterfactual value of $S$ by subtracting from $P_{7}$ through $P_{24}$ the estimated effects of benefit extensions for individuals unemployed for at least 26 weeks in the models with complete controls (Table 3, Panel B, columns 4 and 8) and then recalculating $S$. The impact of benefit extensions on expected duration for affected individuals (job losers unemployed for at least 6 months) is represented by the difference between the observed and counterfactual values of $S$.

Table 7 lists the results of this calculation of expected duration in Panel A, along with a comparison to past estimates in Panel B. The expected durations calculated in months are converted to weeks (months*(52/12)) for direct comparability to past estimates. My estimates indicate that the increase in expected unemployment duration due to a 10-week extension of UI benefits is approximately 1.3 weeks in the 2007-11 episode and a slightly larger 1.6 weeks for the 2000-04 episode. These estimates are in the middle-to-upper end of the range of past estimates listed in Panel B.

The corresponding estimates for expected duration based on the uncorrected transition data are only about half as large as those based on the corrected data used above. 
Table 7 Effects of UI benefit extensions on unemployment duration

\begin{tabular}{|c|c|c|c|}
\hline \multicolumn{4}{|c|}{$\begin{array}{c}\text { Panel A: Estimates for } 10 \text { Extra UI weeks based on Table 3, Panel B, columns } 4 \text { and } 8 \\
\text { (Ul Eligibles, Duration }>=26 \text { Weeks) }\end{array}$} \\
\hline & \multicolumn{2}{|c|}{ Expected duration (weeks) } & \multirow[t]{2}{*}{ Difference (effect of 10 extra UI weeks) } \\
\hline & Observed exits & Counterfactual exits & \\
\hline \multicolumn{4}{|l|}{ Sample period: } \\
\hline 2007-11 & 52.5 & 51.2 & 1.3 \\
\hline \multirow[t]{2}{*}{ 2000-04 } & 45.3 & 43.7 & 1.6 \\
\hline & \multicolumn{3}{|c|}{ Panel B: Estimates from past research (UI administrative data) } \\
\hline Paper: & \multicolumn{2}{|c|}{ Cited estimate } & Effect scaled for 10 extra UI weeks \\
\hline Moffitt (1985) & \multicolumn{2}{|c|}{$\begin{array}{l}\text { Table 4: duration up } 0.16 \text { weeks } \\
\text { with 1-week extension }\end{array}$} & 1.6 \\
\hline Katz and Meyer (1990) & \multicolumn{2}{|c|}{$\begin{array}{l}\text { Abstract: duration up } 0.16-0.20 \\
\text { weeks with } 1 \text {-week extension }\end{array}$} & $1.6-2.0$ \\
\hline Card and Levine (2000) & \multicolumn{2}{|c|}{$\begin{array}{l}\text { Abstract: duration up } 1 \text { week } \\
\text { with 13-week extension }\end{array}$} & 0.8 \\
\hline Jurajda and Tannery (2003) & \multicolumn{2}{|c|}{$\begin{array}{l}\text { Fn. 35: duration up } 1.87 \text { weeks } \\
\text { for } 25 \text {-week extension }\end{array}$} & 0.7 \\
\hline
\end{tabular}

Notes: Panel A based on estimated effects of 10 additional weeks of UI benefits on unemployment exits, from Table 3, Panel B, columns 4 (2007-11) and 8 (2000-04). See text for method.

Using the regression results reported in Additional file 1: Table A3, the increase in expected unemployment duration due to a 10-week extension of UI benefits is approximately 0.7 weeks in the 2007-11 episode and 0.9 weeks for the 2000-04 episode. This is consistent with the shorter overall durations implied by the uncorrected transitions data (Figure 2).

On balance, my results indicate a moderate effect of UI benefit extensions on unemployment duration in the recent episode. As noted in Section 2.1, in 2009 the potential duration of UI benefits reached about 96 weeks for the typical eligible individual. This implies an overall extension of about 70 weeks. Applying the method of Table 5, Panel A to a 70-week extension indicates that the recent extensions increased unemployment duration by about 7.3 weeks (16 percent) for job losers unemployed for at least 6 months.

\section{Conclusions}

I used U.S. labor market survey (CPS) data to estimate the impact of variation in the potential duration of UI benefits arising from benefit extensions that differed across states and over time. I compared the effects from the recent unprecedented extension episode (beginning in 2008) with the earlier, more limited episode from the early 2000s. I focused on the group most likely to be affected by the benefit extensions-job losers unemployed for at least 6 months. The estimated effect of a specific benefit extension on unemployment duration is nearly identical across the two episodes. These estimates suggest that 10 additional weeks of benefits increase unemployment duration by about 1.5 weeks, which is in the middle-to-upper end of the range of past estimates based on U.S. administrative data. ${ }^{26}$ In addition, the estimated effects of benefit duration within each period do not vary based on the state unemployment rate. 
The general absence of variation in the UI extension effect across labor market states is consistent with other recent research (e.g., Schmieder et al. 2012), although it contrasts with the findings of Kroft and Notowidigdo (2011). This likely reflects differences in specific elements of our respective empirical designs, for example Kroft and Notowidigdo's focus on benefit generosity rather than benefit duration. On the other hand, I uncovered evidence suggesting substantial spillover effects to individuals who are ineligible to receive UI benefits, for whom I find higher job finding rates during the recent extension episode in states with very high unemployment rates. I also found, however, that the effects of benefit extensions on unemployment transitions and duration for eligible individuals arise primarily through extended labor force attachment rather than reduced job finding. As such, the source of the spillovers to ineligible individuals is unclear: their increased job finding in response to increases in benefit availability in high unemployment states should be matched by reduced job finding for eligible individuals. Further investigation of potential spillovers using alternative, more precise data sources would be useful.

One open question is the optimality of the unprecedented UI benefit extensions that occurred during the Great Recession and its aftermath in the United States. My finding of little or no impact of the extensions on job finding is relevant in this regard, suggesting that the adverse moral hazard effect of UI on job search is greatly outweighed by the favorable liquidity and social insurance effects (Chetty 2008, Card et al. 2007). Moreover, as Schmieder et al. (2012) argue, the socially optimal duration of UI benefits varies with the inverse of the ratio between the effects of UI extensions on nonemployment duration and the duration of UI benefit recipiency. Given my estimate of a limited impact of extended UI on job finding combined with very high take-up rates for extended UI benefits in recent years, it is likely that optimal UI benefit duration was quite long during the Great Recession and its aftermath. This is an important area for future research.

\section{Endnotes}

${ }^{1}$ Additional program details are provided in periodic reports issued by the U.S. Congressional Research Service, notably Lake (2003), Whittaker and Isaacs (2012), and Isaacs (2013).

${ }^{2}$ The IUR is the three-month average ratio of persons receiving UI benefits to the number of persons covered by the UI system. The TUR is a three-month average of the unemployment rate published by the U.S. Bureau of Labor Statistics (BLS).

${ }^{3}$ The weekly "trigger" notices for the EB program back to 2002 and the complete EUC program are available online at http://www.ows.doleta.gov/unemploy/trigger/ and http://www.oui.doleta.gov/unemploy/euc_trigger/. Similar trigger date information for the TEUC program is no longer available online but was kindly provided to me by Scott Gibbons of the U.S. Department of Labor.

${ }^{4}$ Figure 1 does not reflect several temporary suspensions of the EUC program arising from legislative disagreements that occurred in April, June-July, and December of 2010. During those periods, reauthorization was expected and individuals were allowed to receive benefits through their current EUC tier and retroactive benefits for the next tier after reauthorization. It is therefore likely that the suspension periods did not significantly offset any behavioral responses to the overall 
extension programs. The suspension periods are largely addressed in the empirical analysis through the use of complete monthly date dummies in my econometric equations.

${ }^{5}$ In 2011-13, eight states passed legislation that reduced their normal UI duration below 26 weeks. As an extreme example, in July 2013 North Carolina implemented new legislation that reduced normal UI duration to 19 weeks based on a formula tied to the prevailing state unemployment rate. This and related changes in their state UI laws caused the state to lose eligibility for the federal extensions, reducing total available UI weeks to 19 , as reflected in the minimum weeks plot near the end of the sample frame in Panel A of Figure 1. Reductions in normal UI weeks translate into reduction in available weeks through the EUC and EB programs (see Isaacs 2012). I account for these changes in my database of available UI weeks.

${ }^{6}$ In addition, selected recent work has focused on direct measures of search activity using high-frequency survey or online data from periods corresponding to the recent benefit extensions (Krueger and Mueller 2011, Marinescu 2013). The results from these papers regarding UI extension effects on search intensity and job finding are mixed.

${ }^{7}$ The choice of the 2011 end date is described in Section 2.1.

${ }^{8}$ Rare exceptions to this exact timing can occur, such as during temporary shutdowns of the U.S. federal government (the most recent were during 1995 and late 2013, which are outside my sample frame).

${ }^{9}$ The survivor curves are calculated based on the complete set of available observations, which is larger for the uncorrected transitions due to fewer restrictions placed on the underlying matched sample.

${ }^{10}$ The share of unemployment spells lasting at least six months in the CPS crosssection data is around 30 percent during 2007-11. The discrepancy between the implied durations for my sampled spells and the CPS cross-section is largely due to the impact of flow-based versus stock-based sampling. Simulations provided in Farber and Valletta (2013) show that the empirical flow-based and stock-based duration distributions largely converge in steady state.

${ }^{11}$ Attrition arises in these data because the CPS survey does not track households or individuals who move from their surveyed address. The comparison of the first and second rows in Table 1 ("Currently unemployed" and "Valid matches") illustrates the combined impact of attrition, nonresponse, and the matching validation screen based on demographic characteristics. The implied monthly non-match rate is about 9 percent: matching is feasible for 75 percent (three-fourths) of the sample based on the four-month rotation group structure, but the observation counts in the second row are only about 66 percent of those in the first row on average. Past research reports little or no impact of attrition on longitudinal estimates from matched CPS files (see Neumark and Kawaguchi 2004 for discussion). Moreover, Rothstein (2011, page 162) reports no conditional correlation between the 2008-11 UI extensions and CPS matched sample attrition.

${ }^{12}$ The U.S. unemployment rate averaged 7.6 percent during $2007-11$, with a peak of 10.0 percent in October 2009. By contrast, it averaged 5.2 percent during 2000-04, with a peak of 6.3 percent in June 2003.

${ }^{13}$ Among the sample of ineligibles in both periods, about 60 percent are re-entrants, 15-20 percent are new entrants, and 20-25 percent are job leavers (quits). 
${ }^{14}$ Industry of prior employment is not defined for new labor force entrants; the industry tabulations in the Additional file 1 are restricted to job leavers and re-entrants.

${ }^{15}$ As noted earlier, the date dummies largely account for the potential effects of temporary suspensions of extended benefit (EUC) availability in 2010.

${ }^{16}$ See the Additional file 1: Table A2 for the complete list and corresponding regression results (except the industry categories).

${ }^{17}$ This variation raises the possibility of a regression discontinuity (RD) design for the empirical analysis, in which the pattern of unemployment transitions is compared across individuals in states that are on either side of an unemployment threshold that triggers additional UI extension weeks. Marinescu (2013) implemented an RD strategy using data from online job searches. With my matched CPS data, this strategy would produce observation counts that are too small to yield adequate statistical precision.

${ }^{18}$ Complete coefficient estimates for the column (4) and (8) specifications for eligibles (Table 3) and ineligibles (Table 4) are listed in the Additional file 1: Table A2 (excluding the coefficients on the industry, state, and time dummies).

${ }^{19}$ Job losers unemployed for less than six months are not eligible for extended benefits and hence are not directly affected by the expansions. However, their search intensity may be affected by the expectation of eventual eligibility for extended benefits, implying that they are probably not an appropriate placebo or control group for assessing the effects of extended benefits. The uniformly negative coefficients for this group in Panel B of Table 3 are consistent with this interpretation, although the effects are not precisely estimated.

${ }^{20}$ Industry of prior employment is not defined for new labor force entrants and therefore is excluded from the regressions for the ineligible sample. Results for the eligible sample are nearly identical to those listed in Table 3 when industry controls are excluded from those regressions.

${ }^{21}$ Additional file 1: Table A4 lists parallel results based on the uncorrected transitions. This table shows a mixture of positive and negative coefficients, many of them statistically significant, with different signs across the two sample periods. This pattern likely reflects the unreliability of uncorrected transitions for the ineligible group, which is dominated by labor force entrants, and it precludes reliable inferences.

${ }^{22}$ Similar multinomial logit regressions for the sample of ineligibles produced PBD coefficients that were highly insignificant in all cases.

${ }^{23}$ The calculation yielding a 7.8 percent unemployment rate is the ratio of the PBD and PBD*state unemp. rate coefficients from Panel A: 0.0262/.00334=7.84.

${ }^{24}$ The calculation combining the two coefficients is as follows: $-0.0262+11 *(.00334)=$ 0.0105 .

${ }^{25}$ I truncate durations at 24 months because very few spells are observed beyond that point in my data; accounting for the small number of longer spells does not have a meaningful impact on expected duration.

${ }^{26}$ Rothstein (2011) and Farber and Valletta (2013) translate their estimates into an impact on the overall unemployment rate. For the recent extension period (2008 forward), they find only a modest impact on the unemployment rate, on the order of 0.5 percentage points or less. Based on rough calculations, my estimated PBD responses imply a similar modest effect on the unemployment rate. 


\section{Additional file}

Additional file 1: Supplemental results. Table A1. Descriptive statistics, analysis samples (continued from text Table 2). Table A2. Logit regression results, $\operatorname{Pr}$ (Exit from unemployment), complete specification, UI eligibles and ineligibles (Panel B of Tables 3-4, columns 4 and 8). Table A3. Logit regression results, $\operatorname{Pr}$ (Exit from unemployment), UI ELIGIBLE 1-MONTH TRANSITIONS (UNCORRECTED), marginal effects of 10 additional UI weeks. Table A4. Logit regression results, Pr (Exit from unemployment), UI INELIGIBLE, 1-MONTH TRANSITIONS (UNCORRECTED), marginal effects of 10 additional UI weeks.

\section{Competing interests}

The IZA Journal of Labor Policy is committed to the IZA Guiding Principles of Research Integrity. The author declares that he has observed these principles.

\section{Acknowledgement}

I thank Leila Bengali for excellent research assistance and participants at the October 2013 IZA Workshop on "Labor Market Reforms during the Great Recession" and the February 2014 NBER Labor Studies Conference for comments. I also thank the editor, David Neumark, and an anonymous referee for helpful comments. The views expressed in this paper are those of the author and should not be attributed to anyone else affiliated with the Federal Reserve Bank of San Francisco or the Federal Reserve System.

Responsible editor: David Neumark

Received: 29 October 2013 Accepted: 21 May 2014

Published: 20 Aug 2014

\section{References}

Abowd JM, Zellner A (1985) Estimating Gross Labor-Force Flows. J Bus Econ Stat 3(3):254-283

Baily MN (1978) Some Aspects of Optimal Unemployment Insurance. J Public Econ 10(December):379-402

Card D, Chetty R, Weber A (2007) The Spike at Benefit Exhaustion: Leaving the Unemployment System or Starting a New Job? Am Econ Rev 97(2):113-118

Card D, Levine PB (2000) Extended benefits and the duration of UI spells: evidence from the New Jersey extended benefit program. J Public Econ 78:107-138

Chetty R (2008) "Moral Hazard versus Liquidity and Optimal Unemployment Insurance". J Polit Econ 116(2, April):173-234

Elsby M, Hobijn B, Şahin A, Valletta RG (2011) The Labor Market in the Great Recession: An Update. Brook Pap Econ Act 103(Fall):353-371

Farber HS, Valletta RG (2013) Do Extended Unemployment Benefits Lengthen Unemployment Spells? Evidence from Recent Cycles in the U.S. Labor Market. NBER Working Paper 19048, May. National Bureau of Economic Research, Cambridge, MA

Isaacs KP (2012) Unemployment Insurance: Consequences of Changes in State Unemployment Compensation Laws. Report R41859, Congressional Res Serv, August 15

Isaacs KP (2013) Expiring Unemployment Insurance Provisions. Report R41508, Congressional Res Serv, December 27 Jurajda S, Tannery FJ (2003) Unemployment Durations and Extended Unemployment Benefits in Local Labor Markets. Ind Labor Relat Rev 56(2):324-348

Katz L, Meyer B (1990) The Impact of the Potential Duration of Unemployment Benefits on the Duration of Unemployment. J Public Econ 41(Feb.):45-72

Kroft K, Notowidigdo MJ (2011) "Should Unemployment Insurance Vary with the Local Unemployment Rate? Theory and Evidence." NBER Working Paper 17173, June (updated December). National Bureau of Economic Research, Cambridge, MA

Krueger AB, Mueller A (2011) "Job Search, Emotional Well-Being, and Job Finding in a Period of Mass Unemployment: Evidence from High-Frequency Longitudinal Data". Brooking Papers Econ Activ, Spring 1-57

Lake JE (2003) Unemployment Benefits: Temporary Extended Unemployment Compensation (TEUC) Program. Report RS21397, Congressional Res Serv, January 24

Lalive R, Landais C, Zweimuller J (2013) "Market Externalities of Large Unemployment Insurance Extension Programs". IZA Discussion Paper 7650, September

Landais C, Michaillat P, Saez E (2010) "Optimal Unemployment Insurance over the Business Cycle." NBER Working Paper 16526, November. National Bureau of Economic Research, Cambridge, MA

Levine PB (1993) Spillover Effects Between the Insured and Uninsured Unemployed. Ind Labor Relat Rev 47:73-86

Marinescu I (2013) Online Job Search and Unemployment Insurance during the Great Recession. Manuscript, University of Chicago

Moffitt R (1985) Unemployment Insurance and the Distribution of Unemployment Spells. J Econometrics 28:85-101

Neumark D, Kawaguchi D (2004) Attrition bias in labor economics research using matched CPS files. J Econ Soc Meas 29:445-472

Poterba JM, Summers LH (1986) Reporting Errors and Labor Market Dynamics. Econometrica 54(6):1319-1338

Poterba JM, Summers LH (1995) Unemployment Benefits and Labor Market Transitions: A Multinomial Logit Model with Errors in Classification. Rev Econ Stat 77(2):207-216

Rothstein J (2011) Unemployment Insurance and Job Search in the Great Recession, Brookings Papers on Economic Activity (Fall)., pp 143-196

Rothstein J, Valletta RG (2014) "Scraping By: Income and Program Participation After the Loss of Extended Unemployment Benefits". FRBSF Working Paper, 06 February 2014 
Schmieder JF, Von Wachter T, Bender S (2012) The Effects of Extended Unemployment Insurance over the Business Cycle: Evidence from Regression Discontinuity Estimates over 20 Years. Q J Econ 127:701-752

Schwartz J (2013) Do Temporary Extensions to Unemployment Insurance Benefits Matter? The Effects of the US Standby Extended Benefit Program. Appl Econ 45(March):1167-1183

Sider H (1985) Unemployment Duration and Incidence: 1968-82. Am Econ Rev 75(3, June):461-472

Whittaker JM, Isaacs KP (2012) Extending Unemployment Compensation Benefits During Recessions. Report RL34340, Congressional Res Serv, January 6

Wooldridge JM (2002) Econometric Analysis of Cross Section and Panel Data. MIT Press, Cambridge, MA

10.1186/2193-9004-3-18

Cite this article as: Valletta: Recent extensions of U.S. unemployment benefits: search responses in alternative labor market states. IZA Journal of Labor Policy 2014, 3:18

Submit your manuscript to a SpringerOpen ${ }^{\circ}$ journal and benefit from:

- Convenient online submission

- Rigorous peer review

- Immediate publication on acceptance

- Open access: articles freely available online

- High visibility within the field

- Retaining the copyright to your article

Submit your next manuscript at $\gg$ springeropen.com 